\title{
Viscum album (L.) in experimental animal tumors: A meta-analysis
}

\author{
LEONI VILLANO BONAMIN $^{1}$, ALOISIO CUNHA DE CARVALHO ${ }^{1}$ and SILVIA WAISSE ${ }^{2}$ \\ ${ }^{1}$ Research Center, University Paulista, São Paulo 04026-002; \\ ${ }^{2}$ Department of History of Science, Pontifical Catholic University of São Paulo, São Paulo 01303-000, Brazil
}

Received September 6, 2016; Accepted January 26, 2017

DOI: 10.3892/etm.2017.4372

\begin{abstract}
Mistletoe (Viscum album L.) has been used as complementary anticancer treatment for $\sim 100$ years. Although the clinical efficacy of mistletoe in cancer and associated survival benefits remain contested, several studies point to its effectiveness and others have reported antitumor and immunomodulatory properties. In the present review, a search was conducted for original articles reporting the outcomes of treatments for experimental animal tumors with mistletoe. The inclusion criteria were: Publication in English, from 1996 onwards and in peer-reviewed journals included in the database PubMed. The parameters analyzed were: Provenance and time of publication, rationale, methods (animal species used, mistletoe preparation, treatment protocol, tumor lineage, blinding, randomization, controls and concomitant treatments), outcomes and investigated mechanisms of action. A total of 37 studies met the inclusion criteria. The quality of the studies was adequate in the terms of sample size and use of controls, and the only animal species employed were mice and rats. However, few studies reported having performed random allocation and none reported blinding. There was wide variation in the type and preparation of mistletoe used, route of administration, regimen, tumor type and the mechanism of action assessed. A temporal trend was identified; earlier studies sought to establish the antitumor effect of mistletoe and its possible mechanisms, cytotoxicity and immunomodulation in particular, whereas the later ones tended to focus more on biologically active principles, genomics and oxidative stress. A total of 32/37 studies reported an antitumor effect, 3 of which had mixed results. A total of 2 studies did not detect any antitumor effect and a further 2 found stimulation of tumor growth in the treated groups. One study did not assess antitumor effects, investigating immunomodulation action instead. The quality of the studies was satisfactory and the majority reported positive outcomes. Nevertheless, there is a great deal
\end{abstract}

Correspondence to: Professor Leoni Villano Bonamin, Research Center, University Paulista, 1212 Rua Doutor Bacelar, São Paulo 04026-002, Brazil

E-mail: leonibonamin@unip.br

Key words: Viscum album, experimental oncology, viscotoxins, lectins, review of methodological heterogeneity among the studies, which precludes conclusive comparisons. Based on these results, the present authors strongly suggest developing guidelines for reporting in vivo mistletoe cancer treatment experiments.

\section{Introduction}

Mistletoe (Viscum album L.) has been used for the treatment of various illnesses for centuries (1); however, modern use of mistletoe in cancer treatment was introduced in the 1920s by Rudolf Steiner, the founder of anthroposophy (2). As Kröz et al (3) reported, in 2017 mistletoe will have been used for the treatment of cancer for almost a century, and the significance of this is corroborated by $>1,200$ citations in the PubMed database, which correspond to a multitude of studies demonstrating the immunomodulatory, cytotoxic and proapoptotic, anti-angiogenesis and DNA stabilizing properties of mistletoe. There have also been a number of studies and reviews concerning quality of life and patient perspectives $(4,5)$, evidence-based benefits in human patients $(6,7)$, ongoing clinical studies in humans $(8,9)$ and adverse effects (10).

The mechanism of mistletoe's anticancer action has been of continued interest since its cytotoxic and immunomodulatory qualities were documented in 1990 (11). In the following decade, several studies were concerned with identifying the most effective therapeutic dosage, time and regimen of treatment (12-14). Recently, it has been suggested that mistletoe exerts a potent anti-inflammatory effect via selective inhibition of Cox protein expression, which may contribute to the antitumor action $(15,16)$.

Over time, several biologically active components have been identified, most notably viscotoxins and lectins (ML-I, ML-II, ML-III) (17-21); eventually a recombinant lectin (viscumin, rML) was developed and tested (22-24). Research has also been conducted into lipophilic components, namely triterpenes, which also exhibit marked cytotoxic effects (25-27).

Mistletoe is a semi-parasitic plant that is able to grow on several host trees; the types most frequently used for therapeutic purposes are the ones grown on fir (A-Abies), apple (M-Malus), pine (P-Pinus), poplar (Po-Populus) and oak (Qu-Quercus) trees (2). Asian subspecies of V. album (Korean and Chinese mistletoe, Viscum album subsp. coloratum Kom.) (28) have also been studied and found to have properties similar to European mistletoe. The concentration of active components and biological activity vary as 
a function of the host tree, harvesting time and extraction procedure (aqueous extraction with/without fermentation, other extraction procedures, pressing) (29), which also remain a notable target of research (30).

The clinical efficacy of and survival benefit associated with the use of mistletoe remains contested (31). As is known, the intrinsic complexity of cancer and the composition of mistletoe, pose a problem for clinical trials (2-4). In vivo tumor models may therefore be particularly elucidative, as features of the tumor microenvironment may be observed and compared with the diverse clinical outcomes. The authors of the present study were able to locate a single review on this topic; however, it was limited to breast and gynecological tumors (29). Another source of relevant information is an NIH/National Cancer Institute overview of the use of mistletoe in anticancer treatment, in which the results of studies involving animal models are discussed (32). As there are no recent reviews of mistletoe treatment in animal models, the current study presents a meta-analysis of the peer-reviewed, published literature on the effect of mistletoe in animal cancer models (in vivo models).

\section{Materials and methods}

Literature search. A literature search was performed to locate original research articles reporting the outcomes of mistletoe treatments for experimental tumors in animals. The search was limited to articles published from 1996 onwards, in English, in peer-reviewed journals included in the database PubMed (ncbi. nlm.nih.gov/pubmed/) and with relevant references cited. The aim of this was to facilitate access to the raw data for the interested readership. These criteria were adopted as a considerable number of studies are published in German and/or as books or meeting proceedings, and the peer-reviewed criterion ensures a priori the quality of articles. Several searches were performed using the following search terms: '(Viscum OR mistletoe) AND cancer'; '(Viscum OR mistletoe) AND tumor'; and 'Viscum album AND tumor AND animal'. Only articles reporting in vivo animal models were considered for inclusion.

Parameters of analysis. The parameters of analysis were as follows: i) Provenance and time of publication; ii) rationale underlying the study; iii) methods used [studied animal species, number analyzed, type of mistletoe/mistletoe-derived preparations used, treatment protocol, grafted tumor lineage (epithelial, mesenchymal, melanoma), blinding, random group allocation, controls (placebo, reference drug) and other combined therapies] iv) results (remission, improvement, worsening and survival) and v) mechanisms of action investigated (antiproliferative activity, cytotoxicity, immunomodulatory, tumor leukocyte infiltration, expression of specific phenotypic markers, and other tumor microenvironment aspects likely to correlate with the reported outcomes).

Data presentation. The data were entered in an ad hoc form and are presented in two tables. Table I lists the articles reporting in vivo studies with detailed descriptions of the substance used, dose and regimen, animal model tested, tumor cell lines, concomitant treatments and outcomes. Table II describes methodological aspects used to determine the quality of studies.

\section{Results and discussion}

Initial findings. The literature search located 911 articles. Duplicates were excluded and the remaining studies were analyzed based on their titles and abstracts until 37 remained that met the inclusion criteria and were considered for the present analysis. These 37 studies were written in English, published in peer-reviewed journals from 1996 onward and included in PubMed (mean, 1.85 studies/year; range, 0-7). As mentioned above, only 1 similar review was located for comparison to the present study (29), which assessed 34 studies from 1938 to 2008 (mean, 0.48 studies/year) of which 21 had been published in peer-reviewed journals. The apparently favorable trend detected in the present review should be considered cautiously, as Kienle et al (29) considered breast and gynecological tumors only. However, according to those same authors $\sim 50$ articles/year are published on mistletoe, implying that the proportion of studies using in vivo animal models is rather low. Tables I and II describe the results corresponding to the analyzed parameters.

Mistletoe origin. Viscum album (L.) is a parasitic plant whose composition may be influenced by the host plant or the harvest season (2). As a result of this, the commercially available preparations are typically made from mixtures of fresh leafy shoots harvested in both summer and winter, and fruits harvested in winter, when the concentration of the main active principles (lectins and viscotoxins) is highest (28). Only two studies included in the present review reported the harvest season, and this was reported as winter in both $(27,33)$. A total of 32 studies used European mistletoe and 5 studies used Korean/Chinese mistletoe. The host species on which mistletoe was grown were reported as follows: 13 studies on apple, 4 on oak, 4 on pine, 4 on fir, 2 on poplar and 1 on plum (Prunus) trees. A total of 12 studies did not report the host species.

Distribution per date of publication. A total of 25 studies were published between 1996 and 2005 (mean, 2.5 studies/year) and 12 from 2006 to 2016 (mean, 1.2 studies/year). This is a $50 \%$ decrease in the period 2006-2016 compared with the number of studies published in the previous decade. One hypothesis that could explain such a decrease in the number of studies is the trend towards reducing animal protocols in cancer research (34) due to their poor translational features, but this remains to be confirmed.

Country. The majority of studies were conducted in Germany (20 in their entirety, >37 including multicenter studies), followed by Croatia, India and Korea (4 in each), Austria, Belarus, Brazil, Canada, China, France, Norway, Romania, Serbia and the UK (1 in each). Compared with the review by Kienle et al (29), in which studies originated in Germany, Switzerland, Austria, USA, India, Croatia and Serbia only, the distribution reported here represents a favorable trend, as it seems to denote a more global interest in the use of mistletoe.

Animal species. Mice and rats were used in 32 and 5 studies, respectively. This finding is similar to the one reported by Kienle et al (mice, 28; rats, 6) (29); however, as shown herein, 


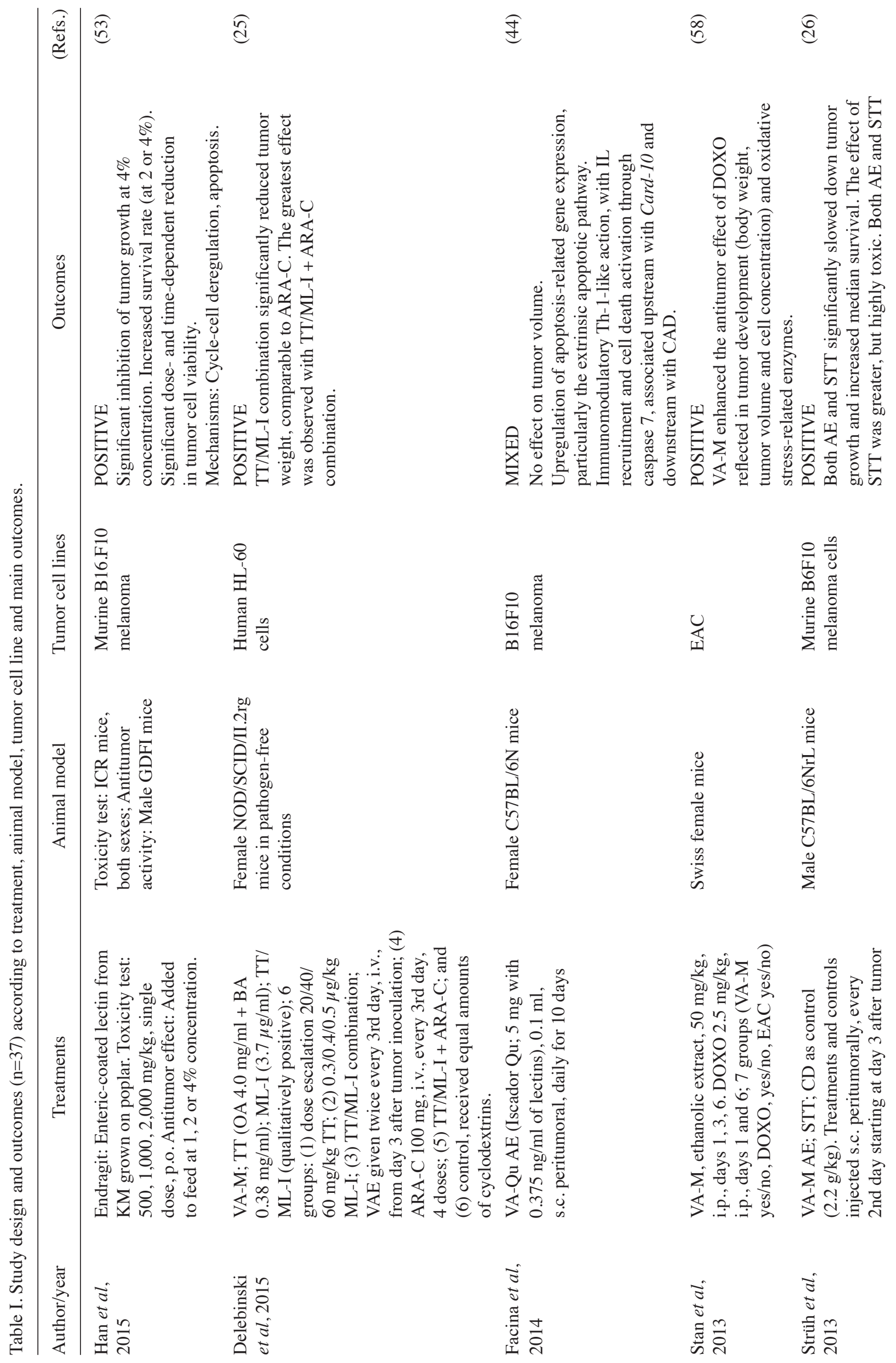




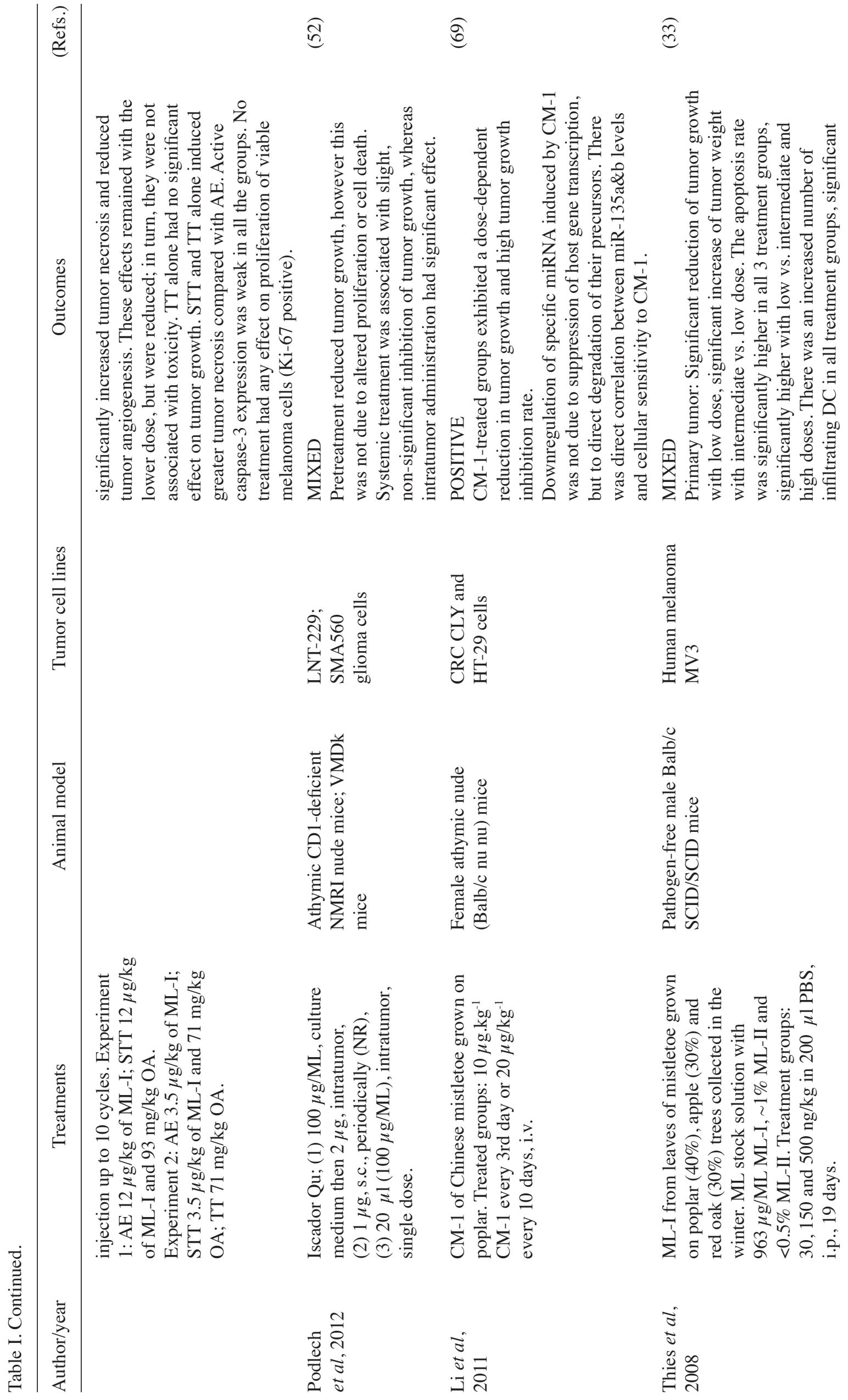




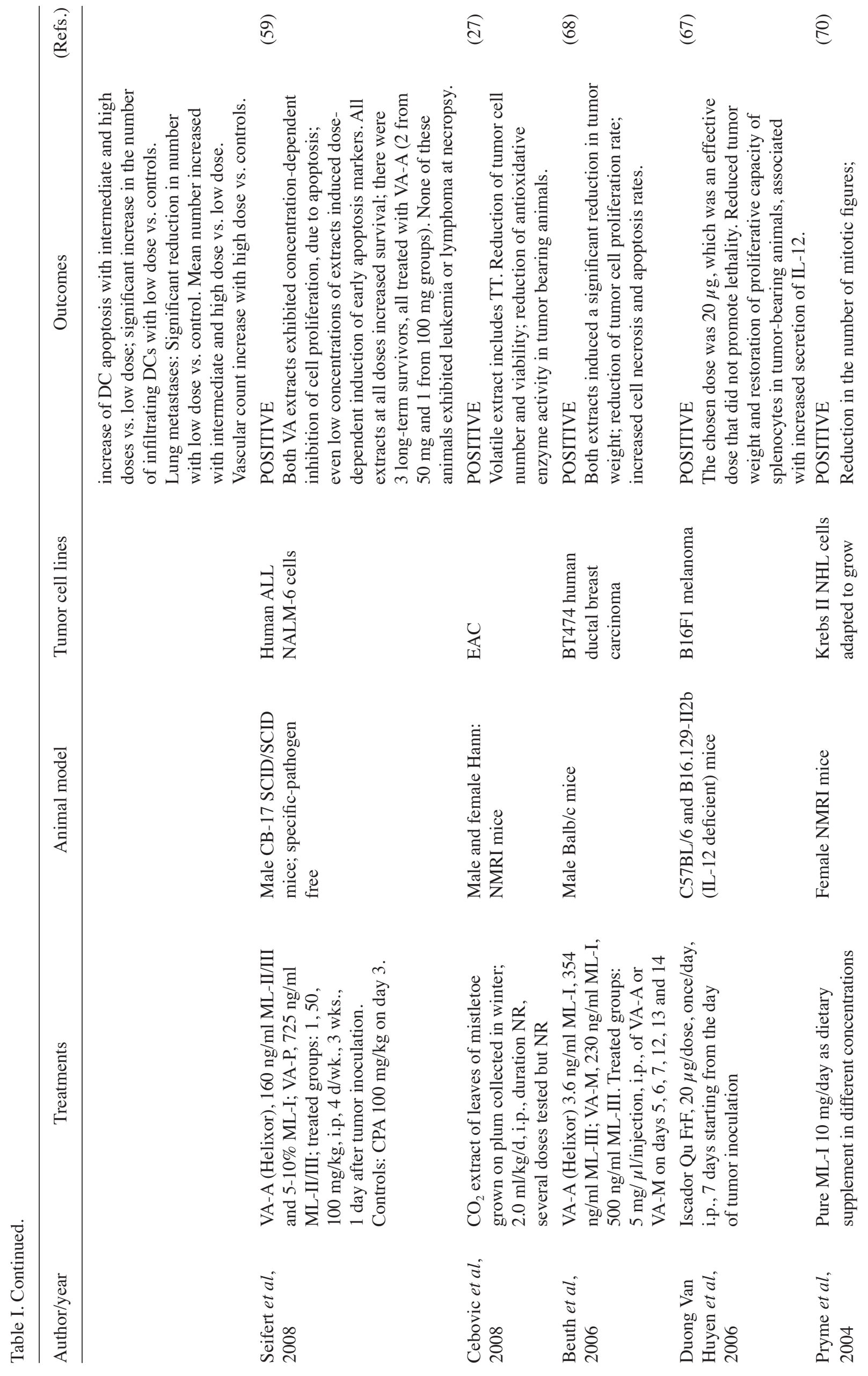




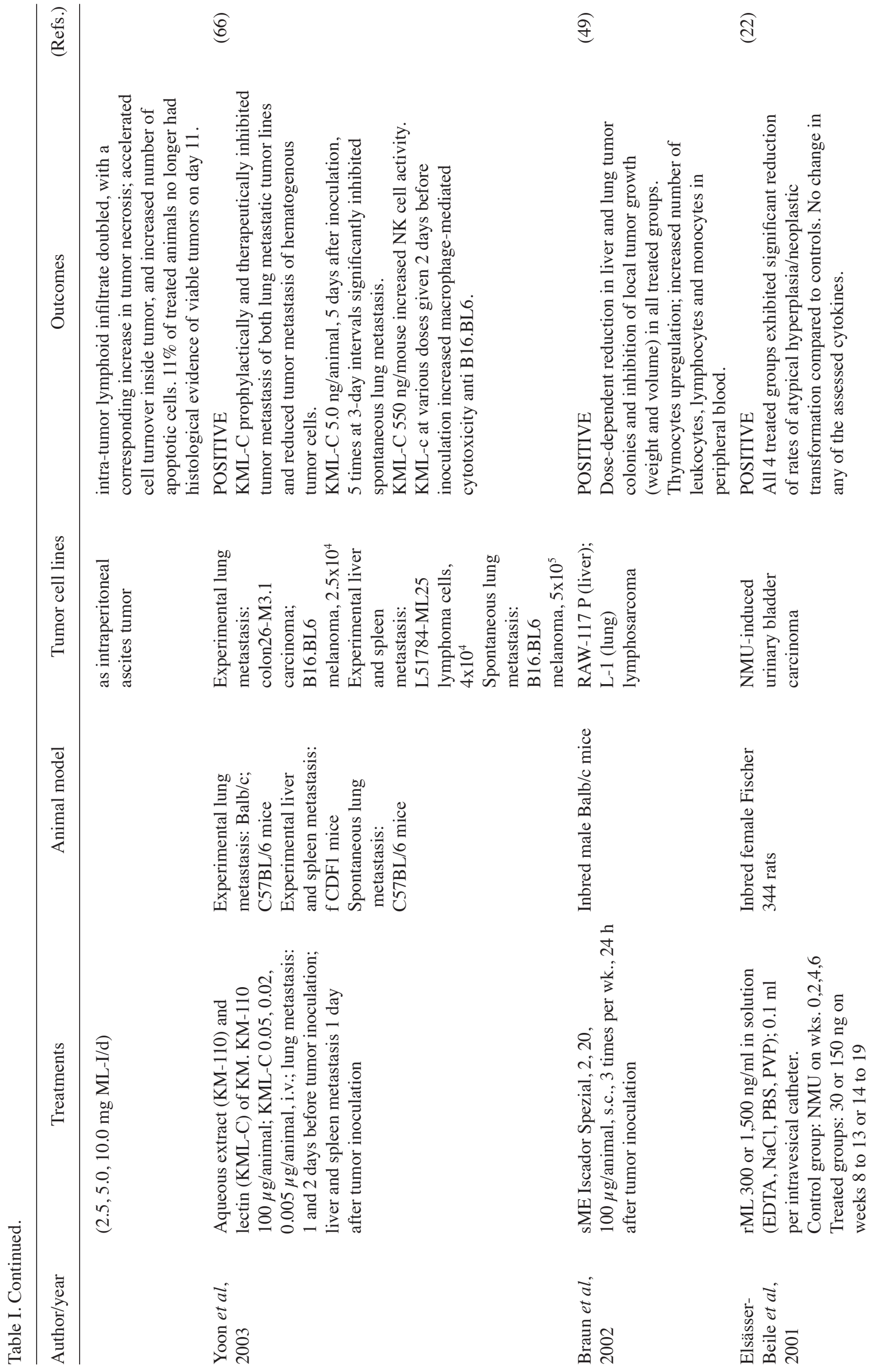




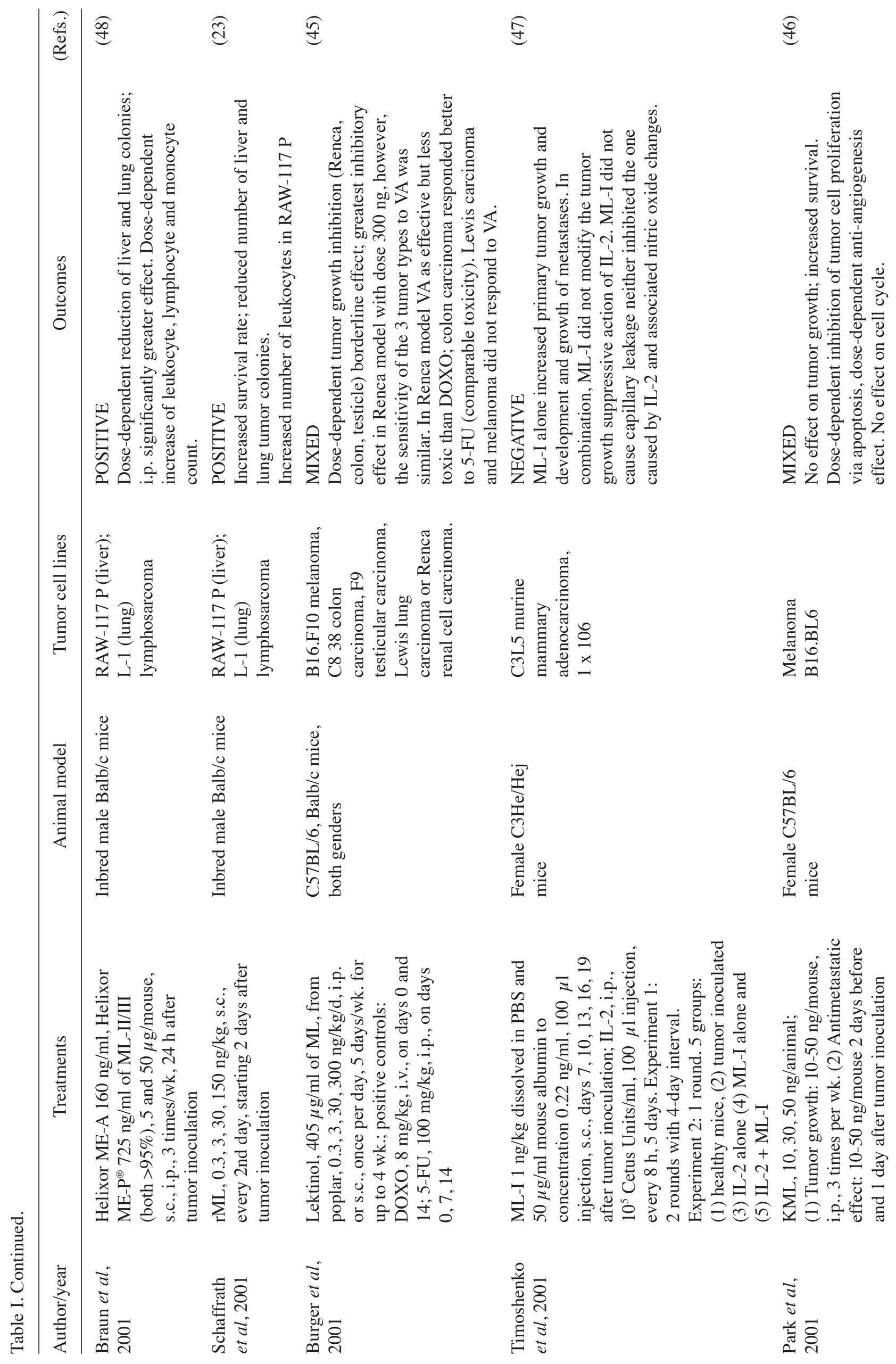




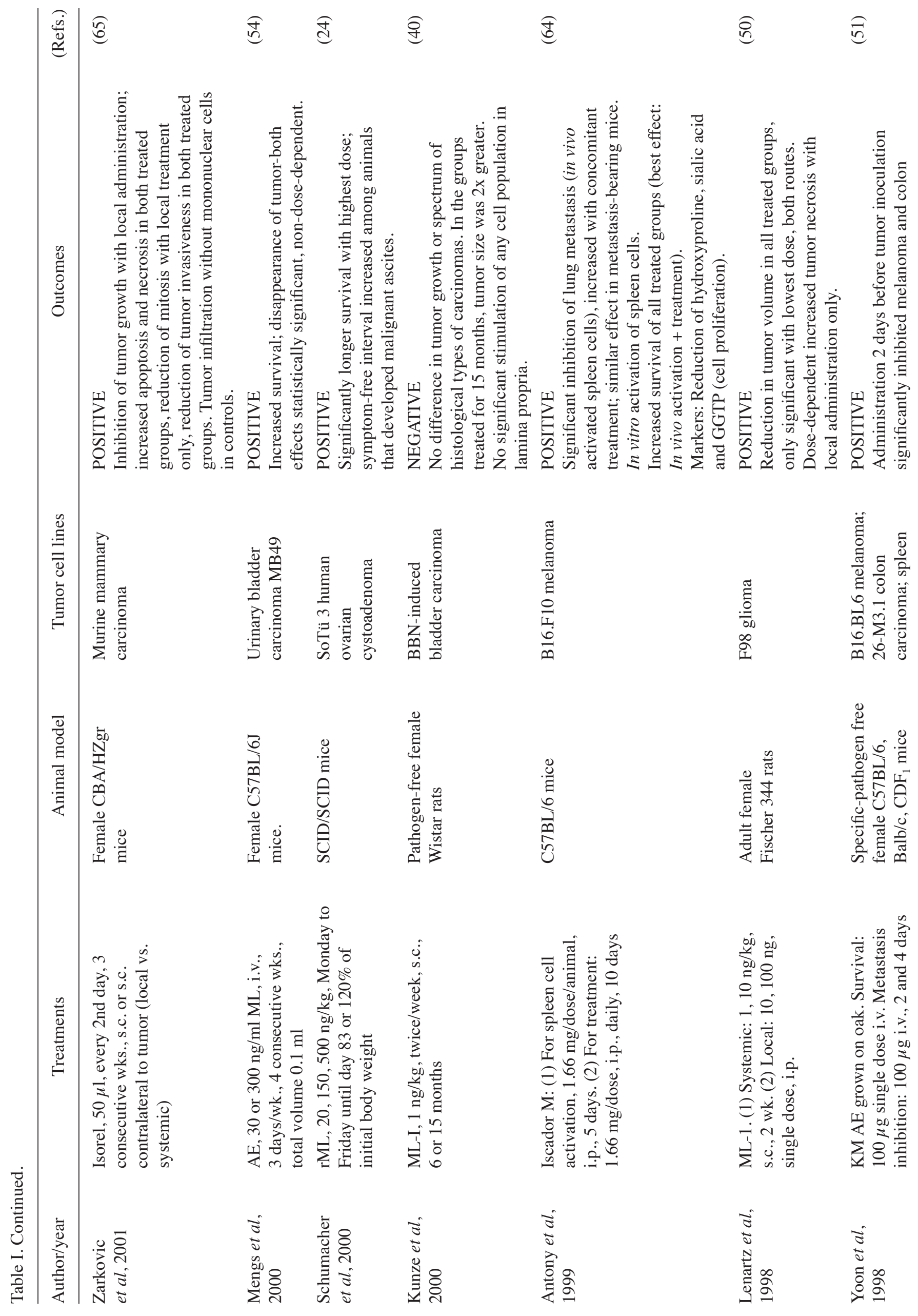




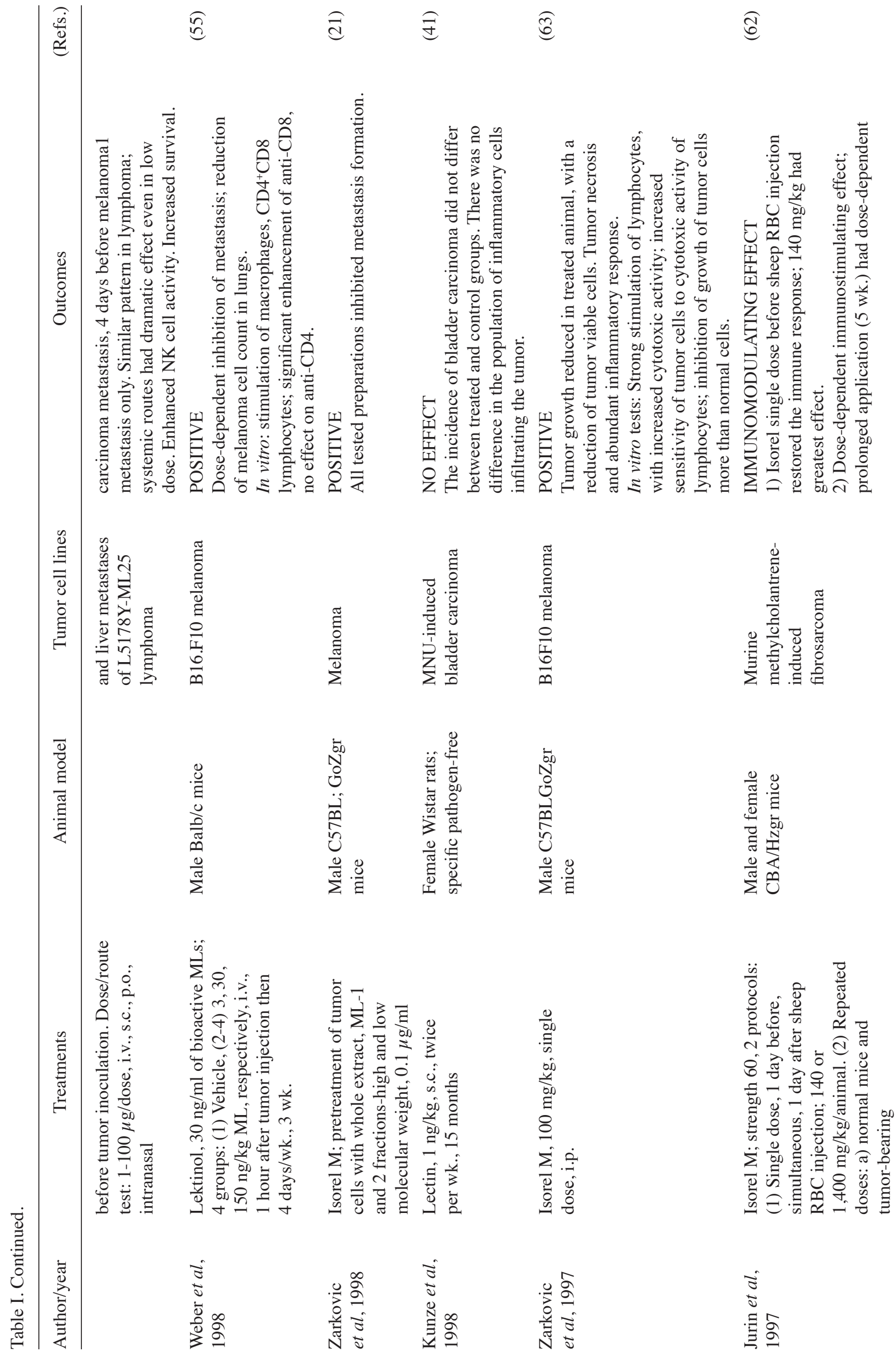




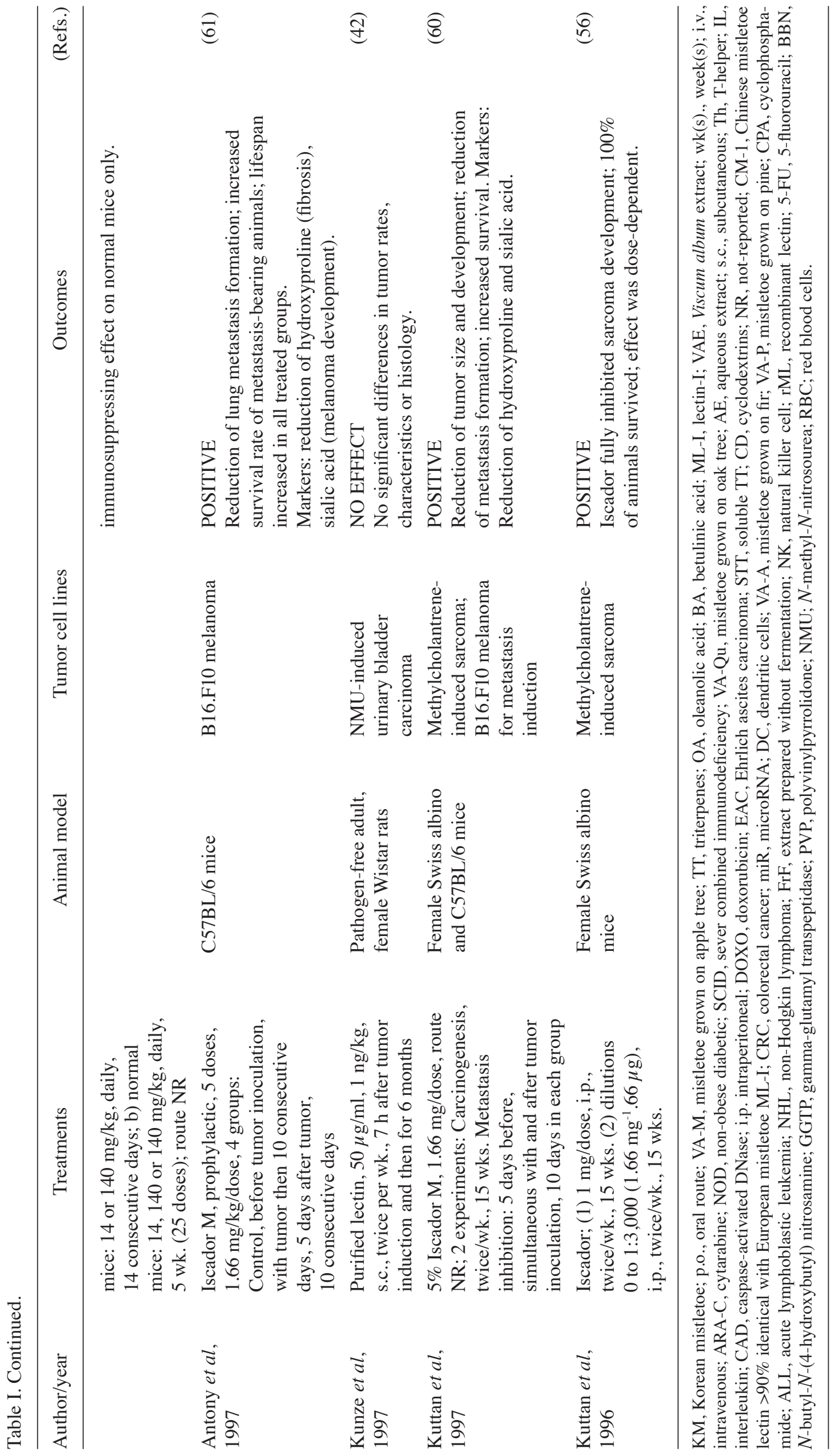




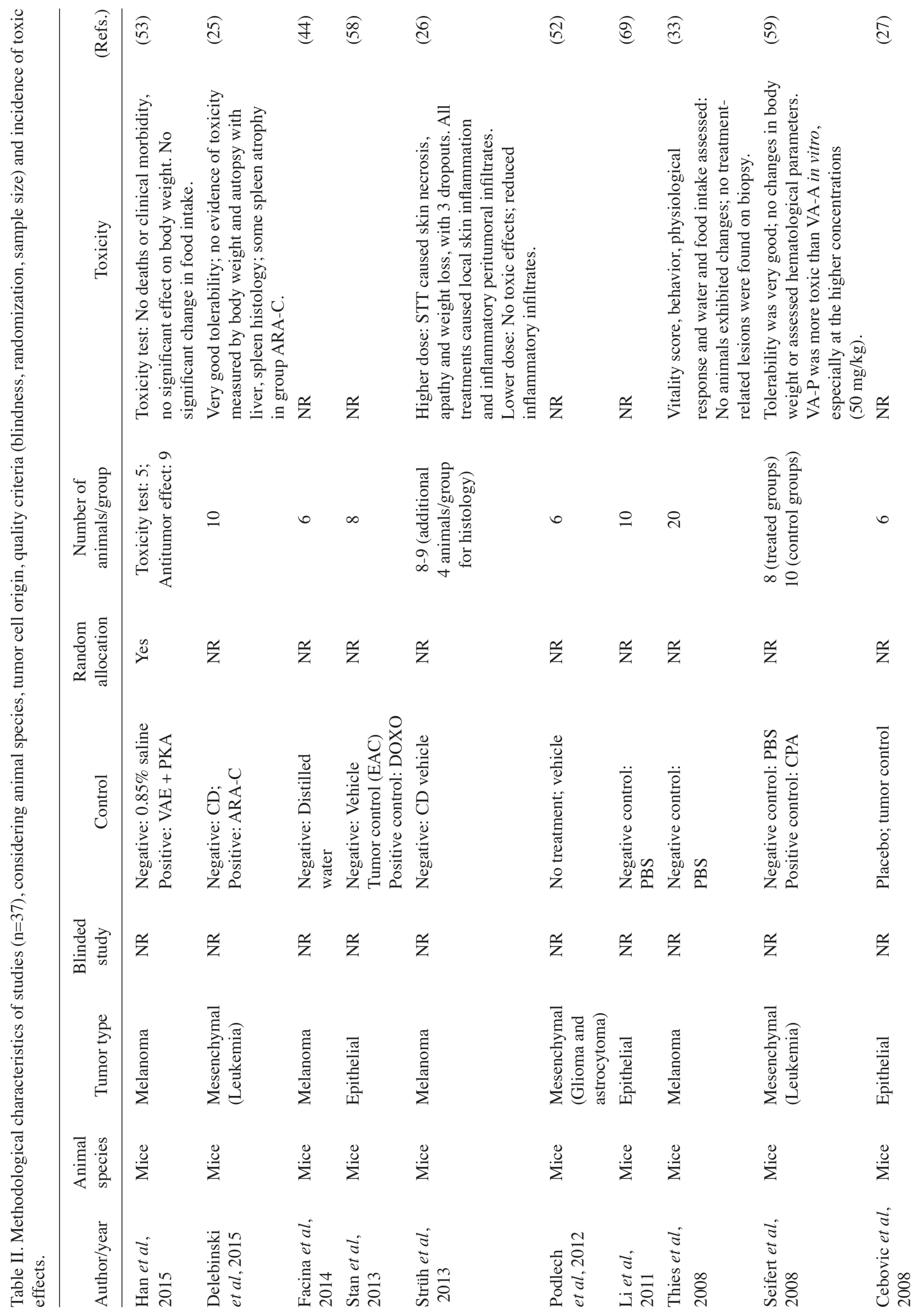




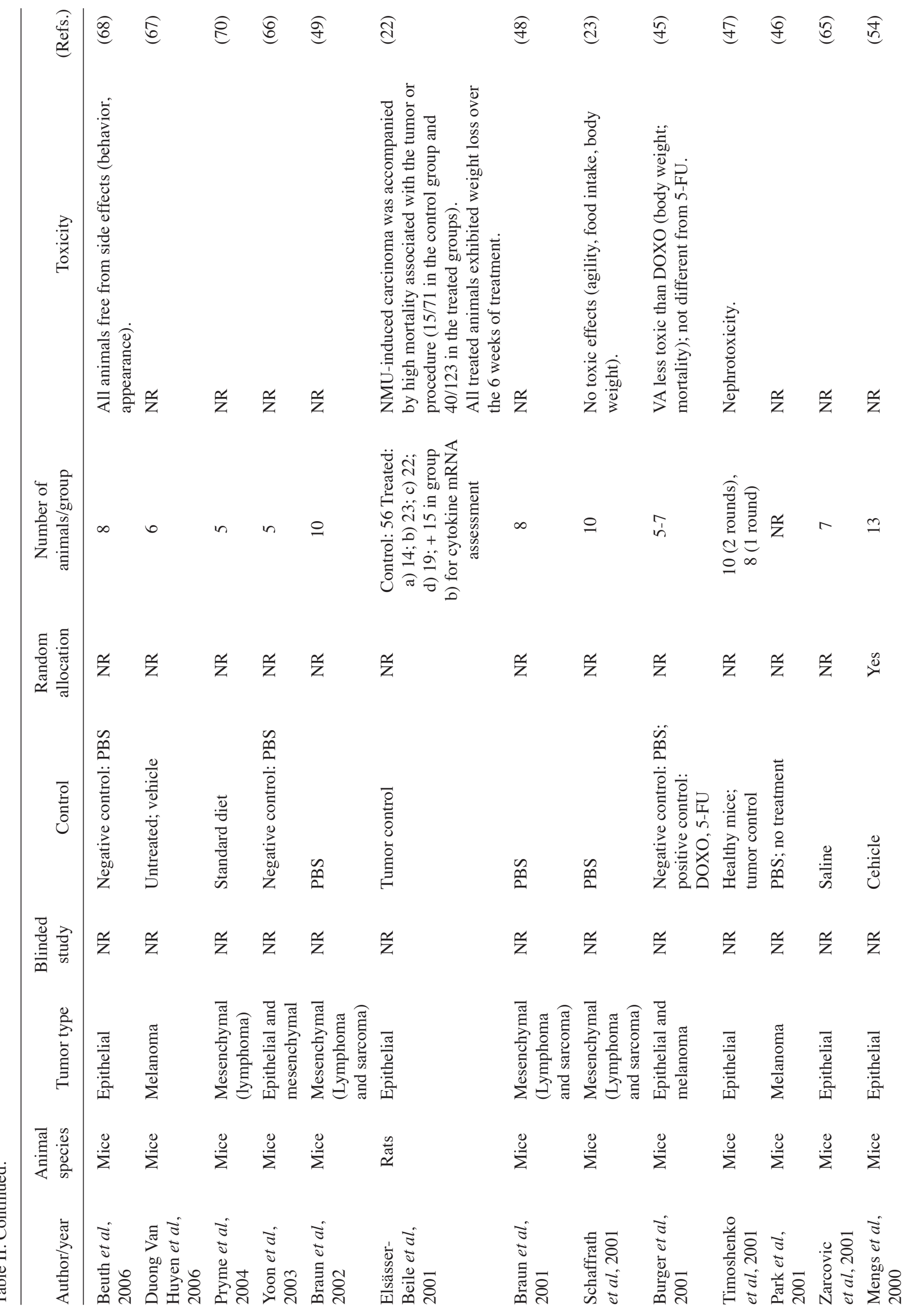




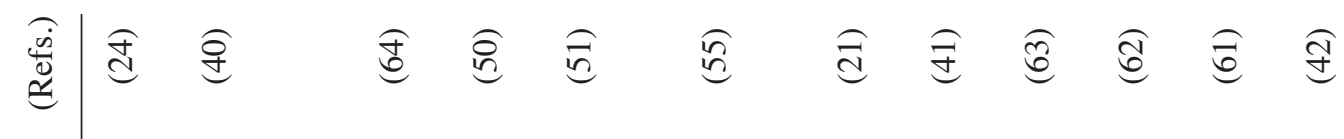

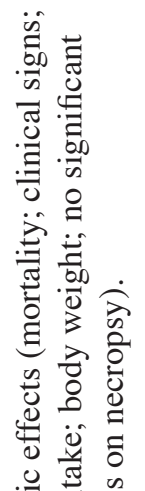

تֶ,

:

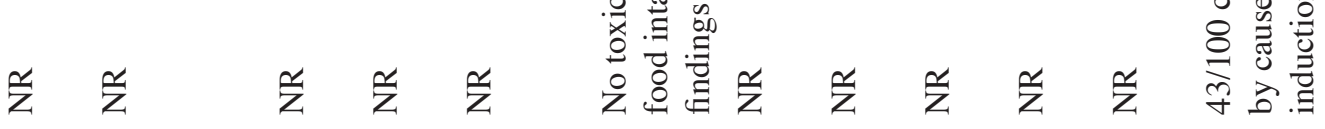

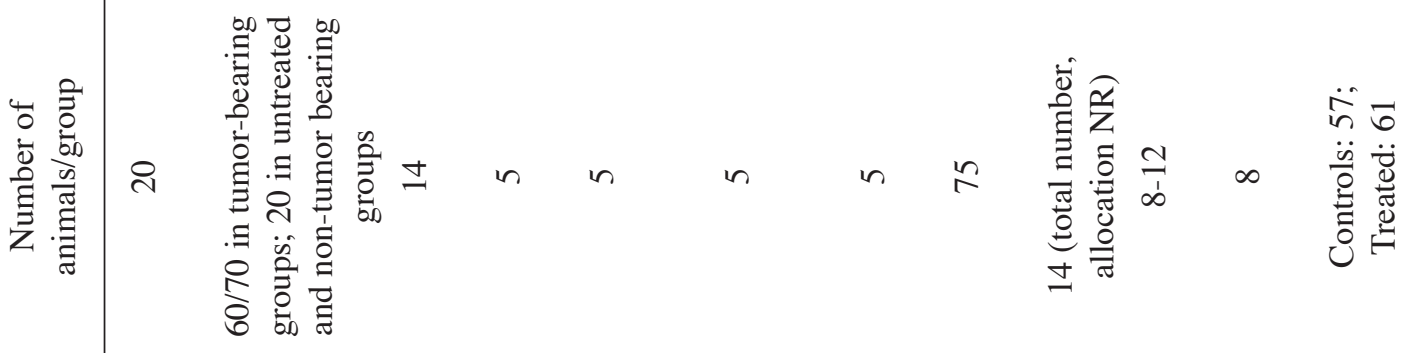

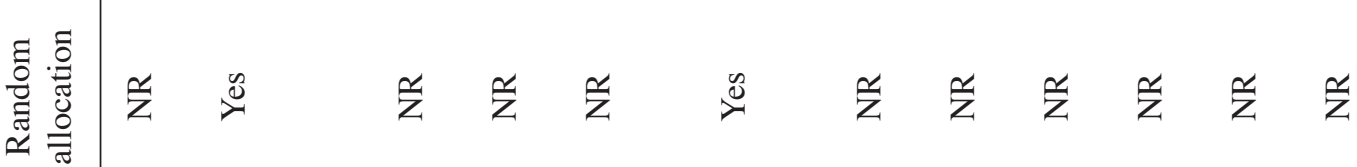

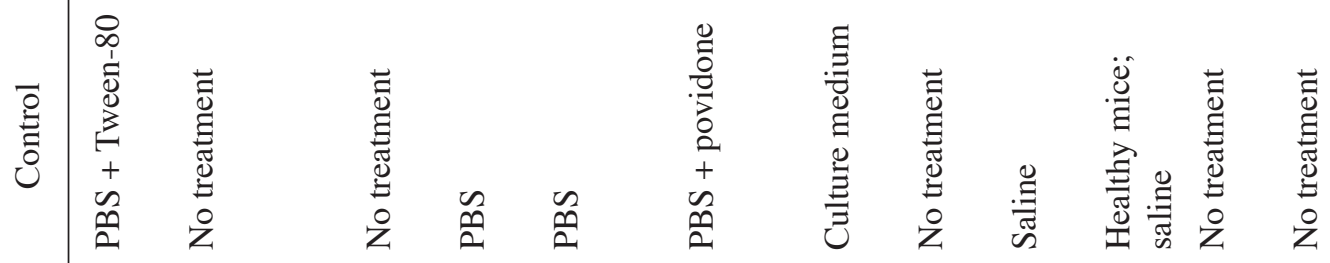

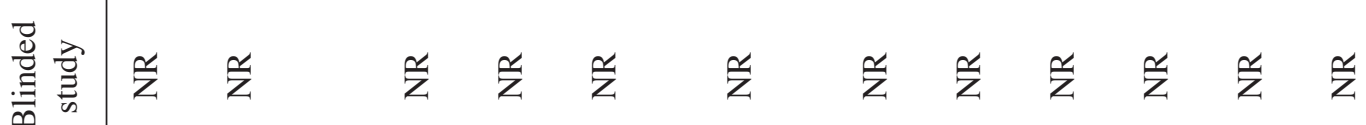

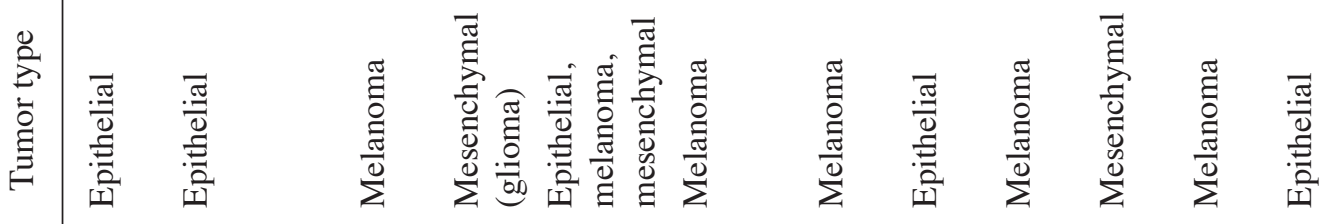

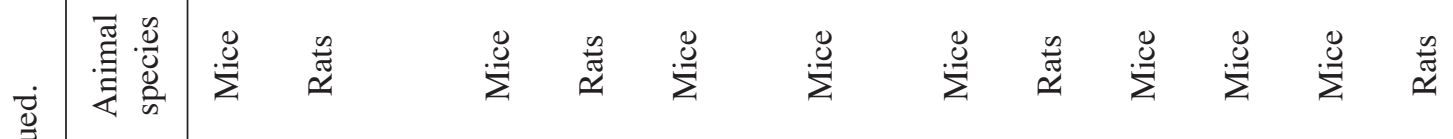

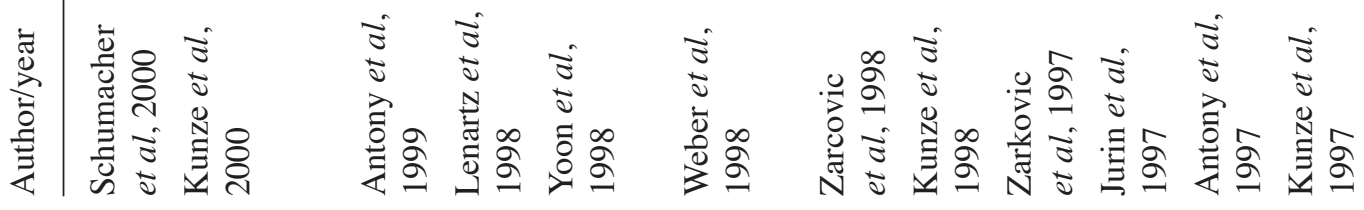


in recent decades mice have become the model used in almost all studies of antineoplastic drugs. This fact raises critical questions as to the translational aspects of such studies and the real possibility of extrapolating experimental findings to clinical practice with humans and other animal species $(34,35)$. Such issues notwithstanding, veterinary clinical studies have demonstrated that mistletoe extracts elicit effective responses in various other animal species (36-39).

Number of animals per group. The number of animals included in each study ranged from 5 to 20 (median, 8), excluding 4 studies that induced autochthonous urinary bladder carcinoma (22,40-42), which included a large numbers of animals in the control and treated groups (range, 20-100). The possible reason for this may be the notably high procedure-related mortality, as is discussed below. These findings agree with those of Kienle et al ( $\mathrm{n}=5$ to 20) (29) and can be rated adequate according to the current standards (43); however, it should be noted that none of the studies presented a justification for the sample size used.

Tumor type. There was an even distribution of tumor types in the studies, including the following: 14 in melanoma cell lines, 15 in epithelial cell lines and 13 in mesenchymal cell lines. Only 7 studies reported negative or no effects relative to models of melanoma (44-46) or epithelial tumors $(40-42,45,47)$. The toxic effects reported were rare and unrelated to the type of tumor. One study reported skin inflammation and necrosis, mainly peritumoral (26) in mice bearing melanoma, whereas 2 studies revealed weight loss in rats and nephrotoxicity in mice bearing epithelial tumors $(22,47)$.

Preparations. A total of 23 studies used whole plant extracts, 13 used lectins alone, 4 used recombinant lectin I, 3 used triterpenes and 1 used a high and low molecular fraction $>$ and $<30 \mathrm{kDa}$; total number is $>37$ as some studies tested more than one substance either alone or in combination). These findings differ from the ones reported by Kienle et al (29): Whole plant extracts $=24$; lectins $=2$; and recombinant lectins $=2$. There is a clear tendency towards increased use of isolated active components, lectins in particular, and the previous interest in other isolated proteins and polysaccharides (4 each) appears to have been replaced by lipophilic components.

Route of administration. A total of 36 studies tested mistletoe administered via various systemic routes (intraperitoneal, oral, intranasal, intravenous, subcutaneous) and 5 at the local tumor site. Three studies pretreated the tumor cells and 4 did not report the route used. These results show a tendency towards systemic administration compared to the results of the study by Kienle et al (29), in which the frequency of systemic and local administration was similar (17 vs. 15 studies, respectively).

A total of 3 studies compared the subcutaneous (SC) and intraperitoneal (IP) routes of administration. In the Braun et al study (48), a reduction in the number of lung and liver colonies of RAW-117 P (liver) and L-1 (lung) lymphosarcoma was obtained only with IP administration of aqueous extract standardized for ML-II/III; however, in a later study they used the SC route only and obtained less positive results (49). Lenartz et al (50) reported a reduction in F98 glioma volume 
for both the SC and IP routes, but tumor necrosis was observed in the animals treated with IP administration only. This supports the hypothesis that IP administration leads to better pharmacokinetics of the main active compounds. Nevertheless, Burger et al (45) compared the SC and IP routes in F9 testicular carcinoma and did not find a difference in the antitumor effect.

Yoon et al (51) compared a variety of dosages (1-100 $\mu \mathrm{g})$ of aqueous extract of Korean mistletoe via various routes-systemic (intravenous, subcutaneous) and mucosal (oral and intranasal). Systemic administration induced a dramatic inhibition of colon carcinoma even at a very low dose $(2 \mu \mathrm{g})$. Furthermore, mucosal routes were associated with metastasis inhibition at a low dose and significantly, no antitumor effect was detected with higher doses via the intranasal route. One study (52) used lectin-rich extract (Iscador Qu) to investigate the effects of pretreatment on tumor cells, systemic and local treatment. Pretreatment mitigated tumor growth, indicating that the antitumor effects mistletoe extract were transferred in vivo to growing tumors; however, this effect was not due to reduced cell proliferation or increased cell death. While intratumor treatment significantly reduced tumor growth, systemic administration had no significant effect.

Taken together, the results are highly variable and divergent, and no definite conclusions can be drawn. With that proviso, there do appear to be indications that local administration may be more effective (see below).

Reported random allocation. Only 5 of the 37 studies included reported having randomly allocated the animals to the experimental groups (40,53-56), whereas in the Kienle et al (29) review, 6 of 31 studies reported randomization. Randomization is a crucial step in any experimental protocol, particularly in the case of complementary medicine as the risk of false positive or false negative results is very high (57). It may therefore be beneficial if a methodological guideline were formulated, as it has been for homeopathic studies (57). In the present review, as well as in the Kienle et al review (29), none of the included studies reported whether blinding was performed or not. It has been suggests that this is not reported as it is a standard procedure (29). However, unlike in clinical studies, the use of blinded protocols in pharmacological basic research is very rare. For example, in the present review, searching the key works 'animal model' and 'blind protocol' in PubMed only identified 94 articles. This is another point to be considered in a putative guideline.

Controls/combination therapy. All 37 studies included control groups, as follows: 26 studies used a placebo-saline/distilled water (5), vehicle (18) or culture medium (1); 12 compared to untreated (10) and/or healthy mice (3). A total of 5 studies comparedmistletoe with standard chemotherapy/adjuvant drugs (polysaccharide $\mathrm{K}$, cytarabine, doxorubicin, cyclophosphamide, 5-fluorouracil) alone or in combination $(25,45,53,58,59)$; and 1 study compared with interleukin- 2 alone and in combination (47).

Aims of studies. The objectives of the studies exhibit clear temporal trends. Studies conducted between 1996 and 2005 sought to establish the antitumor effect of mistletoe and its possible mechanisms, cytotoxicity and immunomodulation in particular (21,46,54-56,60-68), eventually with comparison to or in combination with standard chemotherapeutic agents. By the end of the $1990 \mathrm{~s}$, the focus of studies shifted towards the study of lectins, in particular ML-I $(21,50)$, also including Korean mistletoe $(46,51,53,66)$. Between 2000 and 2001, novel studies concerning recombinant lectin were beginning to be published (22-24); however, the specific effects of lectins II and III began to be explored later $(48,49)$. The overall profile of studies performed in the past decade is notably different to previous studies, tending to investigate biologically active principles $(33,53,59,69)$ including lipophilic ones, in particular triterpenes (25-27). A shift can be also noticed in investigations of the putative mechanism of action, with a stronger focus on genomics $(44,52,69)$ and oxidative stress $(27,28)$.

Side-effects/toxicity. A total of 12 of 37 studies ( 30\%) specifically investigated side effects as variables of interest, including mortality $(45,53,55,56)$, clinical morbidity $(26,53,55)$, body weight $(22,23,25,53,55,56,59)$, food intake $(23,33,53,55,56)$, water intake (33), histology on necropsy $(25,26,33,55)$, behavior $(26,33,68)$, vitality score (33), physiological response (33), hematological parameters (59), overall appearance (68) and agility (23). The majority of studies reported no significant toxic findings, the exception being a study by Strüh et al (26) in which the highest tested dose of solubilized triterpenes administered SC peritumorally resulted in skin necrosis and apathy, which led to 3/13-14 dropouts. Furthermore, animals in all the treated groups exhibited skin inflammation and peritumoral inflammatory infiltrating cells. In the Seifert et al study (59), mistletoe grown on pine trees proved to be more toxic compared to that grown on fir. In the Burger et al study (45) mistletoe was demonstrated to be considerably less toxic than doxorubicin, but showed no differences compared with 5-fluorouracil.

It is worth noting that in the studies using $N$-methyl- $N$ nitrosourea (NMU)-induced autochthonous bladder urinary carcinoma the tumor-induction procedure and complications caused high mortality, ranging from 20 to $50 \%(22,41,42)$. In a later study, Kunze et al $(40)$ employed $N$-butyl- $N$-(4-hydroxybutyl)-nitrosamine (BBN) as a tumor inducer; although the procedure-related mortality was significantly lower ( 0 to $11 \%$ ), the number of animals that developed tumors was also low, as is discussed below.

Outcomes. A total of 32/37 studies reported some antitumor effect, 3 of which had mixed results. Facina et al (44) did not detect any changes in tumor volume due to mistletoe treatment, however they did demonstrate evidence of genetic regulation of apoptosis. Burger et al (45) reported a dose-dependent reduction in tumor growth for 3 of the tested cell lines, but no effect on the other 2 lines tested. In Park et al study (46), mistletoe was demonstrated to have no effect on tumor growth; however, it did induce dose-dependent inhibition of metastasis and led to a slight increase in survival rates. Two studies reported no antitumor effect $(41,42)$ and 2 reported an overt negative effect in the treated groups $(40,47)$. Finally, 1 study assessed immunomodulatory activity only, with no investigation of antitumor effects (62); the results from this study indicated that treatment with mistletoe restored the immune response, 
however prolonged application also had a dose-dependent immunosuppressing effect on normal cells. The relationship between the concentration of active molecules and the balance between cytotoxicity and immunomodulatory effects requires further investigation; the combination of both factors in the same protocol may be a useful tool to treat aggressive tumors with mistletoe components.

A total of 21 studies assessed tumor growth inhibition. Of these, 17 found a reduction in tumor size, 7 of them in a dose-dependent manner and with eventual inversion of the effect at a higher dose (33), and one of these studies (45) indicated a reduction in tumor size in only 3 out of the 5 tested cell lines. In 1 study, remission was reported when mistletoe was administered inside the tumor, whereas there was no such effect when it was administered via the systemic route (52). Two studies reported an unexpected increase in tumor size in the treated groups $(40,47)$. Future studies investigating the underlying molecular mechanisms may explain these paradoxical results.

Survival was analyzed in a total of 12 studies, and was higher in the treated groups in all cases, most of them in all studied doses but dose-dependence was reported in 2 studies $(24,56)$.

Inhibition of primary or metastatic tumor formation was assessed by 1 (56) and 12 studies, respectively. Tumorigenesis was inhibited in all studies with the exception of Timoshenko et al (47). Based on these findings, the authors of the present study suggest that the action of mistletoe active principles in the tumor microenvironment should be investigated further, as the onset of the metastasis-formation process depends on it. Additionally, the variability of results among the different studies may also be attributed to the fact that most protocols were based on transplantable tumors, in which tumorigenesis cannot be evaluated, since tumor cells are inoculated directly in the animals, being immunogenic stimuli. The cases that are most illustrative of this are the 4 studies that assessed the effect of mistletoe lectin on autochthonous urinary bladder carcinoma. Kunze et al $(41,42)$ and Elsässer-Beile et al (22) induced tumors using NMU, and Kunze et al (40) induced tumors with BBN. In all 3 studies by Kunze et al, a lectin isolated from unspecified mistletoe was used. Of these, the 2 studies that induced tumors with NMU had a high procedure-related mortality, and no significant difference was found between the control and treated groups. In contrast, the study that used BBN had a very low procedure-mortality rate, but also a low number of induced tumors in the control and treated groups (n=6 and 4, 10.2 and 6.7\%, respectively, in the 6-month experiment; $n=16$ and 13, 25.8 and $19.7 \%$, respectively, in the 15-month experiment). In this case, at 15 months, the tumor size was twice larger, on average, in the lectin-treated group. Elsässer-Beile et al (22) used recombinant lectin starting 8 or 14 weeks following tumor induction and reported significantly lower rates of atypical hyperplasia and neoplastic transformation in all treated groups compared with the control. The main difference between these two groups of experiments is that Kunze et al used the subcutaneous route for long periods of time (6 and 15 months), whereas Elsässer-Beile et al (22) applied shorter 6 -week treatments via the local route of administration (intravesical instillation). It could therefore be that the divergence in these results is due to the methodological differences between the studies. Mengs et al (54) used the intravesical route to administer a lectin-rich aqueous mistletoe extract to mice implanted with urinary bladder carcinoma MB49 cells in a short 4-week course of treatment; the results of this study indicated a dose-dependent statistically significant tumor growth inhibition in the treated groups.

Several putative mechanisms for the anticancer action of mistletoe were tested, including tumor cell viability [reduced, $(27,53,63)$ ] and number [reduced, (37)]; tumor cell turnover [increased, (70)]; antiproliferative effect [4 studies, no effect in 1 (26)]; proapoptotic action (increased in 8 studies); increased tumor necrosis (6 studies); increased macrophage cytotoxicity (66); reduction of mitotic figures in tumor cells $(65,70)$; cycle cell regulation [deregulated in one study (53), and no effect in another (46)]. Furthermore, 1 study reported degradation of specific miRNAs, this being an indirect effect (affection of precursors) (71) and 2 studies reported a reduction in oxidative stress $(27,58)$.

Reduced tumor invasiveness was reported by 1 study (65), whereas in another (70), $11 \%$ of the treated animals exhibited no histological evidence of viable tumors on day 11 after the onset of treatment. Reduced angiogenesis was identified in 2 studies $(26,46)$; however, in 1 study, the vascular count increased when high doses were used (33). The possible underlying antineoplastic mechanisms require further investigation using specific molecular methods in animal models, as developing an effective mistletoe anticancer agent may on the addition of different mechanisms, possibly associated with a mixture of active molecules in different concentrations and their interactions with the tumor microenvironment. Few studies have been performed from this perspective; a total of 5 studies analyzed the role of local cell infiltrates in tumor development, with an increase in absolute numbers of infiltrating leukocytes being found in 3 studies $(23,63,70)$ and no significant effect found in 2 studies $(40,41)$.

For the immunomodulatory action of mistletoe, induction of the Th-1 response was assessed and detected in 1 study (44) and cytokines were assessed in 2 , of which 1 reported no effect (22) and the other reported upregulation of IL-12 only (67). An increase in natural killer cell activity was detected in 2 studies $(51,66)$. Macrophage stimulation was reported in 1 study (55) and 2 studies found an increase in white cell count in the peripheral blood, but not of granulocytes $(48,49)$. Upregulation of the number of thymocytes (49), activation of spleen cells (64), lymphocyte stimulation $\left(\mathrm{CD}^{+}\right.$and $\mathrm{CD}^{+}$, but only anti $\mathrm{CD}^{+}$activity was enhanced) (55) and finally stimulation of cytotoxic population (63) were also reported.

In conclusion, the majority of studies investigating the effects of mistletoe in animal cancer models analyzed in the present review reported positive outcomes in terms of the inhibition of tumor formation and growth. However, there is considerable methodological heterogeneity among studies, which precludes performing conclusive comparisons and explains the variation in results. A great deal of research is still required with standardization of mistletoe preparation, dose, concentration, regime of administration, length of treatment, targeted cancer type, and other aspects. Similarly, while it is universally assumed that mistletoe has cytotoxic and immunomodulatory effects, there is a wide variation among studies in terms of the mechanisms assessed. The present review found little or no continuity within 
and among research groups, with little progress being made in the past 20 years of studies with experimental animal models. Based on these results, the present authors suggest that the community of interested researchers should develop a guideline for reporting in vivo mistletoe cancer treatment experiments.

\section{Acknowledgements}

The authors of the present study would like to thank the Library of Hiscia Institute, Arlesheim, Switzerland, and Library of the School of Medicine, University of São Paulo, Brazil, for the help in the retrieval of articles. The authors would also like to thank Stephan Baumgartner, Claudia Scherr and Maria Olga Kokornaczyk for their helpful comments on the manuscript.

\section{References}

1. Carpernaros Z: The golden bough: The case for mistletoe. Eur J Herbal Med 1: 19-24, 1994.

2. Marvibaigi M, Supriyanto E, Amini N, Abdul Majid FA and Jaganathan SK: Preclinical and clinical effects of mistletoe against breast cancer. Biomed Res Int 2014: 785479, 2014.

3. Kröz M, Kienle GS, Feder G, Kaveri S and Rosenzweig S: Mistletoe: From basic research to clinical outcomes in cancer and other indications. Evid Based Complement Alternat Med: 987527, 2014.

4. Evans M, Bryant S, Huntley AL and Feder G: Cancer patients' experiences of using mistletoe (Viscum album): A qualitative systematic review and synthesis. J Altern Complement Med 22: 134-144, 2016.

5. Tröger W, Galun D, Reif M, Schumann A, Stanković N and Milićević M: Quality of life of patients with advanced pancreatic cancer during treatment with mistletoe: A randomized controlled trial. Dtsch Arztebl Int 111: 493-502, 2014.

6. Sunjic SB, Gasparovic AC, Vukovic T, Weiss T, Weiss ES, Soldo I, Djakovic N, Zarkovic T and Zarkovic N: Adjuvant cancer biotherapy by Viscum album extract Isorel: Overview of evidence based medicine findings. Coll Antropol 39: 701-708, 2015.

7. von Schoen-Angerer T, Wilkens J, Kienle GS, Kiene H and Vagedes J: High-dose Viscum album extract treatment in the prevention of recurrent bladder cancer: A retrospective case series. Perm J 19: 76-83, 2015.

8. Rose A, El-Leithy T, vom Dorp F, Zakaria A, Eisenhardt A, Tschirdewahn $\mathrm{S}$ and Rübben $\mathrm{H}$ : Mistletoe plant extract in patients with nonmuscle invasive bladder cancer: Results of phase Ib/IIa single group dose escalation study. J Urol 194: 939-943, 2015.

9. Rexer H: Study for the treatment of nonmuscle invasive bladder cancer: A phase III efficacy trial for intravesical instillation of mistletoe extract in superficial bladder cancer (TIM) - AB 40/11 of the AUO. Urologe A: 55: 963-965, 2016 (In German).

10. Steele ML, Axtner J, Happe A, Kröz M, Matthes H and Schad F: Adverse drug reactions and expected effects to therapy with subcutaneous mistletoe extracts (Viscum album L.) in cancer patients. Evid Based Complement Alternat Med 2014: 724258, 2014.

11. Kissel D, Jurin M and Zarcovic N: Über die zytostatischen und immunologischen Effekte von Viscum album. Erfahrunsheilkunde 39: 59-66, 1990.

12. Jurin M, Zarković N, Hrzenjak M and Ilić Z: Antitumorous and immunomodulatory effects of the Viscum album L. Oncology 50: 393-398, 1993

13. Beuth J, Ko HL, Gabius HJ and Pulverer G: Influence of treatment with the immunomodulatory effective dose of the beta-galactoside-specific lectin from mistletoe on tumor colonization in BALB/c-mice for two experimental model systems. In Vivo 5: 29-32, 1991.

14. Kuttan G, Vasudevan DM and Kuttan R: Effect of a preparation from Viscum album on tumor development in vitro and in mice. J Ethnopharmacol 29: 35-41, 1990.

15. Saha C, Hegde P, Friboulet A, Bayry J and Kaveri SV: Viscum album-mediated COX-2 inhibition implicates destabilization of COX-2 mRNA. PLoS One 10: e0114965, 2015.
16. Hegde P, Maddur MS, Friboulet A, Bayry J and Kaveri SV: Viscum album exerts anti-inflammatory effect by selectively inhibiting cytokine-induced expression of cyclooxygenase- 2 . PLoS One 6: e26312, 2011.

17. Lyu SY and Park WB: Mistletoe lectin transport by M-cells in follicle-associated epithelium (FAE) and IL-12 secretion in dendritic cells situated below FAE in vitro. Arch Pharm Res 33: 1433-1441, 2010.

18. Lyu SY and Park WB: Mistletoe lectin modulates intestinal epithelial cell-derived cytokines and B cell IgA secretion. Arch Pharm Res 32: 443-451, 2009.

19. Lavastre V, Cavalli H and Girard D: Anti-inflammatory effect of Viscum album agglutinin-I (VAA-I): Induction of apoptosis in activated neutrophils and inhibition of lipopolysaccharide-induced neutrophilic inflammation in vivo. Clin Exp Immunol 137: 272-278. 2004.

20. Lavastre V, Pelletier M, Saller R, Hostanska K and Girard D: Mechanisms involved in spontaneous and Viscum album aggglutin-l-induced human neutrophil apoptosis: Viscum album agglutinin I accelerates the loss of antiapoptotic Mcl-1 expression and the degradation of cytoskeletal paxillin and vimentin proteins via caspases. J Immunol 168: 1419-1427, 2002.

21. Zarković N, Kalisnik T, Loncarić I, Borović S, Mang S, Kissel D, Konitzer M, Jurin M and Grainza S: Comparision of the effects of Viscum album lectin ML-1 and fresh plant extract (Isorel) on the cell growth in vitro and tumorigenicity of melanoma B16F10. Cancer Biother Radiopharm 13: 121-131, 1998.

22. Elsässer-Beile U, Ruhnau T, Freudenberg N, Wetterauer U and Mengs U: Antitumoral effect of recombinant mistletoe lectin on chemically induced urinary bladder carcinogenesis in a rat model. Cancer 91: 998-1004, 2001.

23. Schaffrath B, Mengs U, Schwartz T, Hilgers RD, Beuth J, Möckel B, Lentzen H and Gerstmayer B: Anticancer activity of rViscumin (recombinant mistletoe lectin) in tumor colonization models with inmunocompetent mice. Anticancer Res 21: 3981-3987, 2001

24. Schumacher U, Feldhaus S and Mengs U: Recombinant mistletoe lectin (rML) is successful in treating human ovarian cancer transplanted into severe combined immunodeficient (SCID) mice. Cancer Lett 150: 171-175, 2000.

25. Delebinski CI, Twardziok M, Kleinsimon S, Hoff F, Mulsow K Rolff J, Jäger S, Eggert A and Seifert G: A natural combination extract of Viscum album L. containing both triterpene acids and lectins is highly effective against AML in vivo. PLoS One 10: $\mathrm{e} 0133892,2015$.

26. Strüh CM, Jäger S, Kersten A, Schempp CM, Scheffler A and Martin SF: Triterpenoids amplify anti-tumoral effects of mistletoe extracts on murine B16.f10 melanoma in vivo. PLoS One 8: e62168, 2013.

27. Cebović T, Spasić S and Popović M: Cytotoxic effects of the Viscum album L. Extract on Ehrlich tumour cells in vivo. Phytother Res 22: 1097-1103, 2008.

28. Büssing A (ed). Mistletoe: The Genus Viscum. Harwood Academic Publishgng, Amsterdam, 2000.

29. Kienle GS, Glockmann A, Schink M and Kiene H: Viscum album L. extracts in breast and gynaecological cancers: A systematic review of clinical and preclinical research. J Exp Clin Cancer Res 28: 79, 2009.

30. Baumgartner S, Flückiger H, Kunz M, Scherr C and Urech K: Evaluation of preclinical assays to investigate an anthroposophic pharmaceutical process applied to mistletoe (Viscum album L.) extracts. Evid Based Complement Alternat Med 2014: 620974, 2014.

31. Horneber MA, Bueschel G, Huber R, Linde K and Rostock M: Mistletoe therapy in oncology. Cochrane Database Syst Rev CD003297, 2008.

32. National Cancer Institute: Mistletoe Extracts (PDQ $\left.{ }^{\circledR}\right)$. http:// www.cancer.gov/about-cancer/treatment $/ \mathrm{cam} / \mathrm{hp} / \mathrm{mistletoe-pdq}$. Accessed August 1, 2016.

33. Thies A, Dautel P, Meyer A, Pfüller U and Schumacher U: Low-dose mistletoe lectin-I reduces melanoma growth and spread in a scid mouse xenograft model. Br J Cancer 98: 106-112, 2008.

34. Begley CG and Ellis LM: Drug development: Raise standards for preclinical cancer research. Nature 483: 531-533, 2012.

35. Mansky PJ, Wallerstedt DB, Sannes TS, Stagl J, Johnson LL, Blackman MR, Grem JL, Swain SM and Monahan BP: NCCAM/NCI phase 1 study of mistletoe extract and gemcitabine in patients with advanced solid tumors. Evid Based Complement Alternat Med 2013: 964592, 2013. 
36. Carvalho AC, Porto E and Bonamin L: Canine neurofibrosarcoma treatment with Viscum album in serial dilutions. Int J High Dilution Res 12: 106, 2013.

37. Christen-Clottu O, Klocke P, Burger D, Straub R and Gerber V: Treatment of clinically diagnosed equine sarcoid with a mistletoe extract (Viscum album austriacus). J Vet Intern Med 24: 1483-1489. 2010.

38. Blostin R and Faivre C: Bénéfices du gui fermenté chez le chat après exérèse de fibrosarcome: Résultats d'une étude préliminaire. Phytotherapie 6: 352-358, 2008.

39. Lefebvre GNF, Bonamin LV and Oliveira CM: Treatment of transmissible venereal tumor (TVT) in dogs with Viscum album (Mistletoe) associated to chemotherapy. Clínica Veterinária 12: 78-86, 2007.

40. Kunze E, Schulz H, Adamek M and Gabius HJ: Long- term administration of galactoside-specific mistletoe lectin in an animal model: No protection against N-butyl-N-(4-hydroxybutyl)-nitrosamine-induced urinary bladder carcinogenesis in rats and no induction of a relevant local cellular immune response. J Cancer Res Clin Oncol 126: 125-138, 2000.

41. Kunze E, Shulz H and Gabius HJ: Inability of galactoside-specific mistletoe lectin to inhibit N-methyl-N-nitrosourea-induced tumor development in the urinary bladder of rats and to mediate a local cellular immune response after long-term administration. J Cancer Res Clin Oncol 124: 73-87, 1998.

42. Kunze E, Schulz H, Ahrens H and Gabius HJ: Lack of an antitumoral effect of immunomodulatory galactoside-specific mistletoe lection on N-methyl-N-nitrosourea-induced urinary bladder carcinogenesis in rats. Exp Toxicol pathol 49: 167-180, 1997.

43. Charan J and Kantharia ND: How to calculate sample size in animal studies? J Pharmacol Pharmacother 4: 303-306, 2013.

44. Facina AS, Facina G, Silva IDCG, Gonçalves GA, Almeida FA, Noronha SMR and Nakamura MU: Viscum album modulates apoptotic related genes in melanoma tumor of mice. Am J Mol Biol 4: 49-58, 2014.

45. Burger AM, Mengs U, Schüler JB and Fiebig HH: Anticancer activity of an aqueous mistletoe extract (AME) in syngeneic murine tumor models. Anticancer Res 21: 1965-1968, 2001

46. Park WB, Lyu SY, Kim JH, Choi SH, Chung HK, Ahn SH, Hong SY, Yoon TJ and Choi MJ: Inhibition of tumor growth and metastasis by Korean mistletoe lectin is associated with apoptosis and antiangiogenesis. Cancer Biother Radiopharm 16 439-447, 2001

47. Timoshenko AV, Lan Y, Gabius HJ and Lala PK: Immunotherapy of $\mathrm{C} 3 \mathrm{H} / \mathrm{HeJ}$ mammary adenocarcinoma with interleukin-2, mistletoe lectin or their combination: Effects on tumour growth, capillary leakage and nitric oxide (NO) production. Eur J Cancer 37: 1910-1920, 2001.

48. Braun JM, Ko HL, Schierholz JM, Weir D, Blackwell CC and Beuth J: Application of standardized mistletoe extracts augments immune response and down regulates metastatic organ colonization in murine models. Cancer Lett 170: 25-31, 2001.

49. Braun JM, Ko HL, Schierholz JM and Beuth J: Standardized mistletoe extract augments immune response and down-regulates local and metastatic tumor growth in murine models. Anticancer Res 22: 4187-4190, 2002.

50. Lenartz D, Andermahr J, Plum G, Menzel J and Beuth J: Efficiency of treatment with galactoside-specific lectin from mistletoe against rat glioma. Anticancer Res 18: 1011-1014, 1998

51. Yoon TJ, Yoo YC, Kang TB, Baek YJ, Huh CS, Song SK, Lee KH, Azuma I and Kim JB: Prophylactic effect of Korean mistletoe (Viscum album coloratum) extract on tumor metastasis is mediated by enhancement of NK cell activity. Int J Immunopharmacol 20: 163-172, 1998.

52. Podlech O, Harter PN, Mittelbronn M, Pöschel S and Naumann U: Fermented mistletoe extract as a multimodal antitumoral agent in gliomas. Evid Based Complement Alternat Med 2012: 501796 , 2012.

53. Han SY, Hong CE, Kim HG and Lyu SY: Anti-cancer effects of enteric-coated polymers containing mistletoe lectin in murine melanoma cells in vitro and in vivo. Mol Cell Biochem 408 $73-87,2015$
54. Mengs U, Schwarz T, Bulitta M and Weber K: Antitumoral effects of an intravesically applied aqueous mistletoe extract on urinary bladder carcinoma MB49 in mice. Anticancer Res 20: 3565-3568, 2000.

55. Weber K, Mengs U, Schwarz T, Hajto T, Hostanska K, Allen TR, Weyhenmeyer $\mathrm{R}$ and Lentzen $\mathrm{H}$ : Effects of a standardized mistletoe preparation on metastatic B16 melanoma colonization in murine lungs. Arzneimittleforschung 48: 497-502, 1998.

56. Kuttan G, Menon LG and Kuttan R: Prevention of 20-methylcholantrene-induced sarcoma by a mistletoe extract Iscador. Carcinogenesis 17: 1107-1109, 1996.

57. Stock-Schröer B, Albrecht H, Betti L, Endler PC, Linde K, Lüdtke R, Musial F, van Wijk R, Witt C and Baumgartner S: Reporting experiments in homeopathic basic research (REHBaR)-a detailed guideline for authors. Homeopathy 98: 287-298, 2009.

58. Stan RL, Hangan AC, Dican L, Sevastre B, Hanganu D, Catoi C, Sarpataki O and Ionescu CM: Comparative study concerning mistletoe viscotoxins antitumor activity. Acta Biol Hung 64: 279-288, 2013.

59. Seifert G, Jesse P, Laengler A, Reindl T, Lüth M, Lobitz S, Henze G, Prokop A and Lode HN: Molecular mechanisms of mistletoe plant extract-induced apoptosis in acute lymphoblastic leukemia in vivo and in vitro. Cancer Lett 264: 218-228, 2008.

60. Kuttan G, Menon LG, Antony S and Kuttan R: Anticarcinogenic and antimetastasic activity of Iscador.AnticancerDrugs 8(Suppl 1): S15-S16, 1997.

61. Antony S, Kuttan R and Kuttan G: Effect of Viscum album in the inhibition of lung metastasis in mice induced by B16F10 melanoma cells. J Exp Clin Cancer Res 16: 159-162, 1997.

62. Jurin M, Zarkovic N, Borovic S and Kissel D: Viscum album L. preparation Isorel modifies the immune response in normal and intumour-bearing mice. Anticancer Drugs 8 (Suppl 1): S27-S31, 1997.

63. Zarkovic N, Zarkovic K, Grainca S, Kissel D and Jurin D: The Viscum album preparation Isorel inhibits the growth of melanoma B16F10 by influencing the tumour-host relationship. Anticancer Drugs 8 (Suppl 1): S17-S22, 1997.

64. Antony S, Kuttan R and Kuttan G: Inhibition of lung metastasis by adoptive immunotherapy using Iscador. Immunol Invest 28 : $1-8,1999$.

65. Zarkovic N, Vukovic T, Loncaric I, Miletic M, Zarkovic K, Borovic S, Cipak A, Sabolovic S, Konitzer M and Mang S: An overview on anticancer activities of the Viscum album extract Isorel. Cancer Biother Radiopharm 16: 55-62, 2001.

66. Yoon TJ, Yoo YC, Kang TB, Song SK, Lee KB, Her E, Song KS and Kim JB: Antitumor activity of the Korean mistletoe lectin is attributed to activation of macrophages and NK cells. Arch Pharm Res 26: 861-867, 2003

67. Duong Van Huyen JP, Delignat S, Bayry J, Kazatchkine MD, Bruneval P, Nicoletti A and Kaveri SV: Interleukin-12 is associated with the in vivo anti-tumor effect of mistletoe extracts in B16 mice melanoma. Cancer Lett 243: 32-37, 2006.

68. Beuth J, Ko HL, Schneider H, Tawadros S, Kasper HU, Zimst H and Schierholtz JM: Intratumoral application of standardized mistletoe extracts down regulates tumor weight via decreased cell proliferation, increased apoptosis and necrosis in a murine model. Anticancer Res 26: 4451-4456, 2006.

69. Li LN, Zhang HD, Zhi R and Yuan SJ: Down-regulation of some miRNAs by degrading their precursors contributes to anti-cancer effect of mistletoe lectin-I. Br J Pharmacol 162: 349-364, 2011.

70. Pryme IF, Bardocz S, Pusztai A, Ewen SW and Pfüller U: A mistletoe lectin (ML-I)-containing diet reduces the viability of a murine non-Hodgkin lymphoma tumor. Cancer Detect Prev 28: $52-56,2004$.

71. Lee CH, Kim JK, Kim HY, Park SM and Lee SM: Immunomodulating effects of Korean mistletoe lectin in vitro and in vivo. Int Immunopharmacol 9: 1555-1561, 2009. 